\title{
Anti-obesity Effect of Fermented Whey Beverage using Lactic Acid Bacteria in Diet-induced Obese Rats
}

\author{
Sung-Moon Hong, Eui-Chun Chung, and Cheol-Hyun Kim* \\ Department of Animal Resource \& Science, Dankook University, Cheonan 31116, Korea
}

\begin{abstract}
High-protein fermented whey beverage (FWB) was manufactured using whey protein concentrate (WPC) and Lactobacillus plantarum DK211 isolated from kimchi. This study was designed to evaluate the anti-obesity activity of FWB in male rats fed a high-fat diet. Male Sprague-Dawley rats were randomly assigned to three groups ( $\mathrm{n}=8$ per group). The three groups differed in their diet; one group received a normal diet (ND), another, a high-fat diet (HD), and the third, a HD plus fermented whey beverage (HDFWB), for 4 wk. Supplementation with FWB (the HDFWB group) prevented weight gain and body fat accumulation. The food intake in the HDWFB group was significantly lower $(p<0.05)$ than that of the HD group. The HDWFB group also showed a significant decrease in organ weights $(p<0.05)$, except for the weight of the testis. There was a significant decrease in total cholesterol, LDL-cholesterol, and triglycerides in the HDFWB group compared with the HD group $(p<0.05)$, but there was no significant difference in serum HDL-cholesterol levels among the experimental groups. Rats ingesting FWB (the HDFWB group) also showed a significant decrease in blood glucose levels, and plasma levels of insulin, leptin, and ghrelin compared to HD group $(p<0.05)$. These results indicate that FWB has beneficial effects on dietary control, weight control, and reduction in fat composition and serum lipid level; consequently, it may provide antiobesity and hypolipidemic activity against high fat diet-induced obesity in rats.
\end{abstract}

Keywords: whey protein, obesity, Lactobacillus plantarum, cholesterol, leptin

Received June 23, 2015; Revised August 24, 2015; Accepted August 28, 2015

\section{Introduction}

To maintain body weight in a stable condition, there must be an energy balance; energy intake has to be equal to energy expenditure. However, when the energy balance gets disturbed, this may eventually lead to sustained weight problems, such as obese subjects (Klok et al., 2007). Obesity is primarily considered as a disorder of lipid metabolism as well as a disarray of energy balance. It is one of the major public health problems in the world due to its association with an increased risk of various chronic diseases, including cardiovascular diseases, type 2 diabetes, hypertension, dyslipidemia, and various cancers (Jin et al., 2013). Chronic consumption of a high-fat and highcholesterol diet may induce hyperlipidemia, hepatic lipid accumulation, lipid peroxidation, and hepatotoxicity (Xu et al., 2013).

There are many different treatments to help control obe-

\footnotetext{
*Corresponding author: Cheol-Hyun Kim, Department of Animal Resource \& Science, Dankook University, Cheonan 31116, Korea. Tel: +82-41-550-3656, Fax: +82-41-622-2207, E-mail: hichkim@dankook.ac.kr
}

sity, including diet, exercise, behavior modification, and medication (You et al., 2014). Among these treatments, reducing excessive energy intake might be one of the major ways to correct obesity, but the compliance of energyrestricted diets should not be easy (Yu et al., 2009). Therefore, dietary manipulations maximizing satiety or consumption of food components with adipogenesis-suppressive ability may be obvious applications for the future treatment of the overweight and obese (Yu et al., 2009; Xu et al., 2013).

Consuming more frequent, higher protein meals is a commonly practiced dietary strategy to increase healthy eating and promote weight loss, as well as, the prevention of weight re-gain following weight loss (Douglas et al., 2013). It is well known that dietary protein, compared with high fat and/or high carbohydrate diets, has a higher appetite control and satiety effect, shown by its ability to suppress the subject's caloric intake in subsequent meals (Douglas et al., 2013; Yu et al., 2009). Dairy proteins, especially whey proteins, have been suggested to have a better effect on appetite control than other protein sources, such as egg and casein, and to play a key role as a mediator of beneficial metabolic effects (Pal et al., 2010;

(9)This is an open access article distributed under the terms of the Creative Commons Attribution Non-Commercial License (http://creativecommons.org/licences/ by-nc/3.0) which permits unrestricted non-commercial use, distribution, and reproduction in any medium, provided the original wokr is properly cited. 
Shi et al., 2012). Several animal and clinical studies have shown the effects of whey protein intake on obesity and obesity-related diseases (Belobrajdic et al., 2004; Jakubowicz and Froy, 2013; Pal et al., 2010; Park et al., 2008; Pilvi et al., 2008; Shi et al., 2011; Shi et al., 2012; Siddiqui et al., 2008; Yu et al., 2009).

Several prospective observational studies and clinical studies have been conducted to examine the relationship between dairy product consumption and weight gain or overweight/obesity status (Martinez-Gonzalez et al., 2014). Dairy products intake has shown the beneficial effects on metabolic risk factors in overweight and obese individuals (Pal et al., 2010; Shi et al., 2012). It has been thought that the slenderizing effects of yogurt are due to a probiotic bacteria-mediated mechanism. The relationship between the intestinal environment and host health has been extensively studied since the importance of lactic acid bacteria on good health and longevity has been suggested by Mechinikoff (Ikeda et al., 2014). Lactic acid bacteria are important members of the normal intestinal microflora and are reported to exert beneficial effects, not only for bowel function, but also many biological functions or expressions of diseases, such as serum cholesterol, lipid metabolism, blood pressure, immune system, and obesity (Ikeda et al., 2014; Lee et al., 2013). Therefore, dietary probiotic consumption alters gut microbiota and may be another effective strategy for weight control.

Recently, consumers' interests in ready-to-drink (RTD) protein drinks have increased in the market for sports nutrition, and medical and therapeutic beverages, because of their unique nutritional value, especially abundant supply of essential amino acids for protein synthesis, and excellent functional properties in food products (Rittmanic, 2010; Sanmartin et al., 2013). In previous study (Cho et al., 2015), we developed a functional fermented whey beverage (FWB) manufactured using whey protein concentrates 80 (WPC 80) and Lactobacillus plantarum DK211 isolated from traditional Korean fermented food, and evaluated its functionality and sensory properties. The aim of the present study was to investigate the potential anti-obesity and metabolic effects of FWB through the measurements of body weight gain, organ weights, serum lipid, blood glucose, insulin and appetite-related hormones in high-fat diet-induced obese rats.

\section{Materials and Methods}

\section{Materials}

The strain, Lactobacillus plantarum DKL 121 was iso- lated from kimchi samples, and maintained in glycerol stocks at $-20^{\circ} \mathrm{C}$. Lactococcus lactis (L. lactis R704, Christian Hansen, Denmark) was provided from Jupiter Int. Co. (Korea). Whey protein concentrate (WPC 80) and skim milk were purchased from Sung Poon Co. (Korea) and Seoul Milk (Korea), respectively. Sucrose was obtained from CJ Co. (Korea). MRS broth was purchased from Difco (USA). All other chemicals and reagents used were of analytical grade, and were purchased from Sigma-Aldrich (USA). The general and high-fat diets were purchased from Daehan Biolink Co. Ltd. (Korea), and their formula and nutritionals compositions are shown in Table 1 and Table 2, respectively.

\section{Manufacture of fermented whey beverage}

Fermented whey beverage was prepared using $11 \%$ WPC $80,2 \%$ skim milk powder, and $10.3 \%$ sugar. The mixed culture of Lactobacillus plantarum DK211 and Lactococcus lactis was previously sub-cultured in triplicates in MRS broth at $37^{\circ} \mathrm{C}$. All dry ingredients were dissolved in sterile water and homogenized with a homomixer (IKA, Korea) at 10,000 rpm. This mixture was then pasteurized at $70^{\circ} \mathrm{C}$ for $30 \mathrm{~min}$, cooled to about $40^{\circ} \mathrm{C}$, inoculated culture at a rate of $20 \mathrm{~mL} \cdot \mathrm{L}^{-1}\left(10^{9} \mathrm{CFU} \cdot \mathrm{mL}^{-1}\right)$, and fermented at $37^{\circ} \mathrm{C}$ for $10 \mathrm{~h}$ until the desired $\mathrm{pH}$ of $4.5 \mathrm{had}$ developed. The nutritional composition of final FWB product is shown in Table 2.

Table 1. Composition of the experimental diets fed to rats

\begin{tabular}{ccc}
\hline \hline Component (g/kg) & $\begin{array}{c}\text { Normal diet } \\
(\mathrm{ND})\end{array}$ & $\begin{array}{c}\text { High-fat diet } \\
(\mathrm{HD})\end{array}$ \\
\hline Casein & 210.0 & 265.0 \\
Sucrose & 325.0 & 90.0 \\
Maltodextrin & 50.0 & 160.0 \\
Cellulose & 37.15 & 65.5 \\
Mineral Mix, AIN-93G-MX & 35.0 & 48.0 \\
Vitamin Mix, AIN-93-VX & 15.0 & 21.0 \\
Soybean oil & 20.0 & 30.0 \\
Lard & 20.0 & 310.0 \\
L-Cystine & 3.0 & 4.0 \\
\hline
\end{tabular}

Table 2. Nutritional compositions of the experimental diets and fermented whey beverage (FWB)

\begin{tabular}{cccc}
\hline \hline & $\begin{array}{c}\text { Normal diet } \\
\text { (ND) }\end{array}$ & $\begin{array}{c}\text { High-fat diet } \\
\text { (HD) }\end{array}$ & FWB \\
\hline Energy (Kcal) & 451.4 & 701.5 & 83.8 \\
Protein (\%) & 20.1 & 18.4 & 9.0 \\
Carbohydrate (\%) & 69.8 & 21.3 & 11.5 \\
Fat (\%) & 10.2 & 60.3 & 0.2 \\
Viable cell count & - & - & $9.62 \pm 0.05$ \\
$($ Log CFU/mL) & & & \\
\hline
\end{tabular}




\section{Experimental animals and diets}

Four-week-old male Sprague-Dawley (SD) rats $(n=24)$ with an average body weight of $156.04 \pm 11.74 \mathrm{~g}$ were purchased from Daehan Biolink Co. Ltd. (Korea). The rats were housed in stainless steel cages in a room with controlled temperature $\left(22 \pm 2^{\circ} \mathrm{C}\right)$, humidity $(65 \pm 5 \%)$, and lighting (12 h altering light-dark cycle). Following one week of acclimatization with a pelletized normal diet, rats were randomly divided into three groups as follows: normal diet (ND), high-fat diet (HD) and HD plus FWB (HDFWB). Each experimental group consisted of 8 animals. All mice in the HD and HDFWB groups received a high-fat diet. The mice in the HDWFB group were given the FWB $\left(3,000 \mathrm{mg}^{\bullet} \mathrm{day}^{-1}\right)$ using oral gavage once a day, while the mice in the ND and HD groups were given same amount of saline solution via oral gavage. During the experimental period ( $4 \mathrm{wk}$ ), the rats were given free access to food and water. Food intake was monitored daily, and their body weights were measured once per week. Weight gain was determined from body weight. The experimental design was approved by Experimental Animals Ethics Committee of Dankook University, and the rats were maintained in accordance with their guidelines.

\section{Preparation of organ samples and body fat pads}

At the end of the experimental period, following $12 \mathrm{~h}$ of fasting, the rats were anesthetized with ethyl ether. Blood was collected using a cardiac puncture, and serum was separated by centrifugation at $10,000 \mathrm{~g}$ for $10 \mathrm{~min}$. The serum was stored at $-80^{\circ} \mathrm{C}$ until analysis. The liver, spleen, kidney, and testis were removed to measure the change in weight. The body fat pads of the abdominal and epididymal areas were collected, washed with saline, and weighed.

\section{Measurement of serum lipid levels}

Serum triglyceride (TG), total cholesterol (TC), high density lipoprotein cholesterol (HDL-C), and low density lipoprotein cholesterol (LDL-C) levels were measured using enzyme kits TG, CHOL, HDL-C plus 3rd generation, and LDL-C plus 2nd generation (Roche, Mannheim, Germany), respectively.

\section{Measurement of serum glucose, insulin and appe- tite-related hormones levels}

The concentrations of blood glucose were measured by an enzymatic kinetic assay, using the enzyme kit GLU (Germany). Serum insulin concentrations were measured by an enzyme-linked immunosorbent assay (ELISA) using the Insulin-Rat/Mouse ELISA Kit (Millipore, USA). The major appetite-related hormones, leptin and ghrelin were measured by ELISA using the Mouse Leptin ELISA Kit and Rat/Mouse Ghrelin (Total) ELISA (Millipore, USA), respectively.

\section{Statistical analysis}

For statistical analysis, statistical analysis system (SAS) program was used and data were expressed as the means \pm standard deviation (SD). The significance of differences among the three groups was assessed by Duncan's multiple range test. Results were considered to be significantly different when $\mathrm{P}$ values were $<0.05$.

\section{Results}

\section{Effects of the FWB on body weight changes and food intake}

After the experimental period, the final body weight in HD group was $316.76 \pm 16.15$ g (Table 3 ), consequently, rats in HD group showed a significant body weight gain compared to ND and HDFWB groups $(p<0.05)$. There was no significant difference in the final body weights between ND group (274.78 $\pm 10.54 \mathrm{~g})$ and HDFWB group $(259.28 \pm 19.23 \mathrm{~g})$, but the body weight gain in HDFWB group was lower than that of ND group. Similarly, the food intake in HD group was significantly higher than other two groups $(p<0.05)$.

\section{Effects of the FWB on the weight organs and body fat pads}

The HDFWB group showed significantly lower liver, spleen, and kidney weights compared to the HD group (Table 4). However, no significant increase was observed with the high fat diet on the weight of the kidney. In accor-

Table 3. Body weight changes and food intakes of rats that fed normal diet (ND), high-fat diet (HD), or HD plus fermented whey beverages (HDFWB) during experimental periods

\begin{tabular}{cccc}
\hline \hline & \multicolumn{3}{c}{ Treatment groups } \\
\cline { 2 - 4 } & $\begin{array}{c}\text { Normal diet } \\
\text { (ND) }\end{array}$ & $\begin{array}{c}\text { High-fat diet } \\
(\text { HD) }\end{array}$ & HDFWB \\
\hline Body weight (g) & & & \\
Initial & $156.03 \pm 11.57^{\mathrm{a}}$ & $156.05 \pm 9.39^{\mathrm{a}}$ & $156.04 \pm 14.27^{\mathrm{a}}$ \\
Final & $274.78 \pm 10.54^{\mathrm{b}}$ & $316.76 \pm 16.15^{\mathrm{a}}$ & $259.28 \pm 19.23^{\mathrm{b}}$ \\
Gain & $118.74 \pm 6.02^{\mathrm{b}}$ & $157.75 \pm 13.72^{\mathrm{a}}$ & $103.24 \pm 12.04^{\mathrm{b}}$ \\
Food intake (g/d) & $17.36 \pm 2.36^{\mathrm{b}}$ & $23.01 \pm 3.05^{\mathrm{a}}$ & $17.51 \pm 2.22^{\mathrm{b}}$ \\
\hline Values are expressed as mean $\pm \mathrm{SD}(\mathrm{n}=8)$. & \\
a,b Means with different superscript letter among groups are signif- \\
icantly different at $p<0.05$ by Duncan's multiple range test.
\end{tabular}


Table 4. Effects of the fermented whey beverage (FWB) on organ and fat pad weights of the rats after the experimental period

\begin{tabular}{cccc}
\hline \hline & \multicolumn{3}{c}{ Weights (g) } \\
\cline { 2 - 4 } & $\begin{array}{c}\text { Normal diet } \\
\text { (ND) }\end{array}$ & $\begin{array}{c}\text { High-fat diet } \\
\text { (HD) }\end{array}$ & HDFWB \\
\hline Liver & $9.69 \pm 0.91^{\mathrm{b}}$ & $11.79 \pm 1.73^{\mathrm{a}}$ & $8.76 \pm 1.41^{\mathrm{b}}$ \\
Spleen & $0.77 \pm 0.09^{\mathrm{a}}$ & $0.75 \pm 0.15^{\mathrm{a}}$ & $0.58 \pm 0.11^{\mathrm{b}}$ \\
Kidney & $2.39 \pm 0.29^{\mathrm{a}}$ & $2.41 \pm 0.27^{\mathrm{a}}$ & $1.97 \pm 0.10^{\mathrm{b}}$ \\
Testis & $3.02 \pm 0.20^{\mathrm{a}}$ & $3.06 \pm 0.43^{\mathrm{a}}$ & $2.91 \pm 0.15^{\mathrm{b}}$ \\
$\begin{array}{c}\text { Abdominal and } \\
\text { epididymal fat pads }\end{array}$ & $4.19 \pm 1.51^{\mathrm{b}}$ & $6.48 \pm 1.91^{\mathrm{a}}$ & $3.08 \pm 1.27^{\mathrm{b}}$ \\
\hline
\end{tabular}

Values are expressed as mean \pm SD $(n=8)$.

${ }^{\mathrm{a}, \mathrm{b}}$ Means with different superscript letter among groups are significantly different at $p<0.05$ by Duncan's multiple range test.

Table 5. Effects of the fermented whey beverage (FWB) on serum lipid profiles of the rats after the experimental period

\begin{tabular}{cccc}
\hline \hline \multirow{2}{*}{$\begin{array}{c}\text { Serum lipid levels } \\
(\mathrm{mg} / \mathrm{dL})\end{array}$} & \multicolumn{3}{c}{ Treatment groups } \\
\cline { 2 - 4 } & $\begin{array}{c}\text { Normal diet } \\
\text { (ND) }\end{array}$ & $\begin{array}{c}\text { High-fat diet } \\
(\mathrm{HD})\end{array}$ & \multirow{2}{*}{ HDFWB } \\
\hline Triglyceride & $76.25 \pm 1.54^{\mathrm{b}}$ & $142.75 \pm 5.41^{\mathrm{a}}$ & $65.63 \pm 1.78^{\mathrm{b}}$ \\
Total cholesterol & $84.25 \pm 1.24^{\mathrm{b}}$ & $97.88 \pm 1.95^{\mathrm{a}}$ & $73.75 \pm 2.05^{\mathrm{b}}$ \\
LDL-cholesterol $^{\mathrm{n}}$ & $66.50 \pm 4.21^{\mathrm{b}}$ & $77.88 \pm 1.49^{\mathrm{a}}$ & $56.88 \pm 2.94^{\mathrm{c}}$ \\
HDL-cholesterol & $17.88 \pm 1.59^{\mathrm{b}}$ & $19.38 \pm 4.28^{\mathrm{a}}$ & $16.50 \pm 0.83^{\mathrm{a}}$ \\
\hline
\end{tabular}

Values are expressed as mean $\pm \mathrm{SD}(\mathrm{n}=8)$.

${ }^{\mathrm{a}-\mathrm{c}}$ Means with different superscript letter among groups are significantly different at $p<0.05$ by Duncan's multiple range test.

dance with body weight, the weight of the abdominal and epididymal fat pads was also markedly higher in the HD group compared to the ND and HDFWB groups. The difference between the ND and HDFWB groups with respect to the weight of liver and fat pads did not reach statistical significance.

\section{Effects of the FWB on serum lipid profiles}

It was observed that rats supplemented with FWB (the HDFWB group) for 4 consecutive weeks showed a significant decrease in the levels of serum triglycerides ( 65.63 $\left.\pm 1.78 \mathrm{mg}^{\circ} \mathrm{dL}^{-1}\right)$, total cholesterol $\left(73.75 \pm 2.05 \mathrm{mg}^{\circ} \mathrm{dL}^{-1}\right)$, and LDL-cholesterol $\left(56.88 \pm 2.94 \mathrm{mg} \cdot \mathrm{dL}^{-1}\right)$ compared to the HD group $(p<0.05)$ (Table 5). LDL-cholesterol levels in the HDFWB group were even significantly lower than those of the ND group $(p<0.05)$. No significant differences in the HDL-cholesterol levels among the three groups were observed in this study.

\section{Effects of the FWB on the levels in blood glucose and serum insulin}

As shown in Fig. 1, the fasting blood glucose level and serum insulin level were significantly increased in the HD
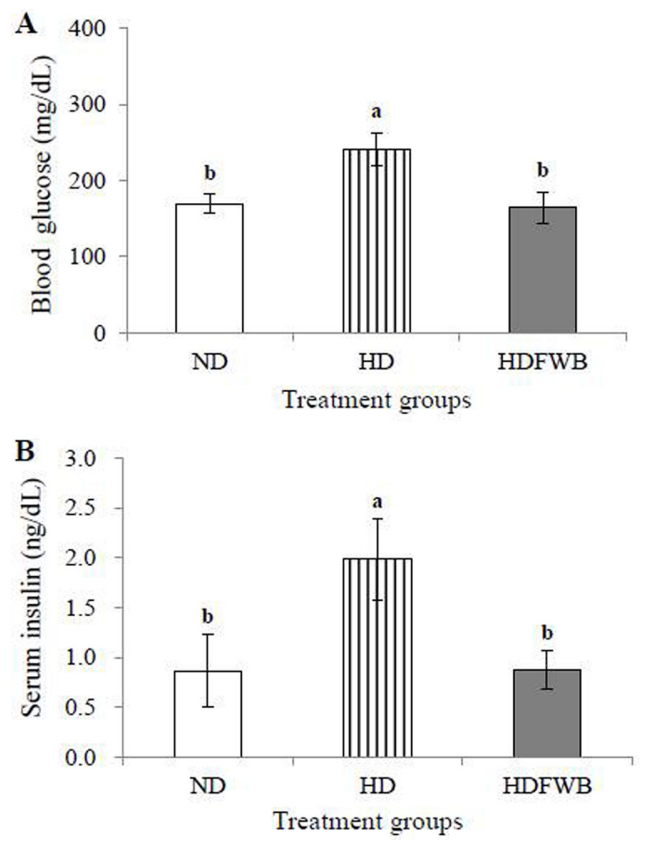

Fig. 1. Blood glucose level (A) and serum insulin level (B) of rats receiving normal diet (ND), high-fat diet (HD) and high-fat and fermented whey beverage diet (HDFWB). ${ }^{\mathrm{a}, \mathrm{b}}$ Means with different superscript letter among groups are significantly different at $p<0.05$ by Duncan's multiple range test.
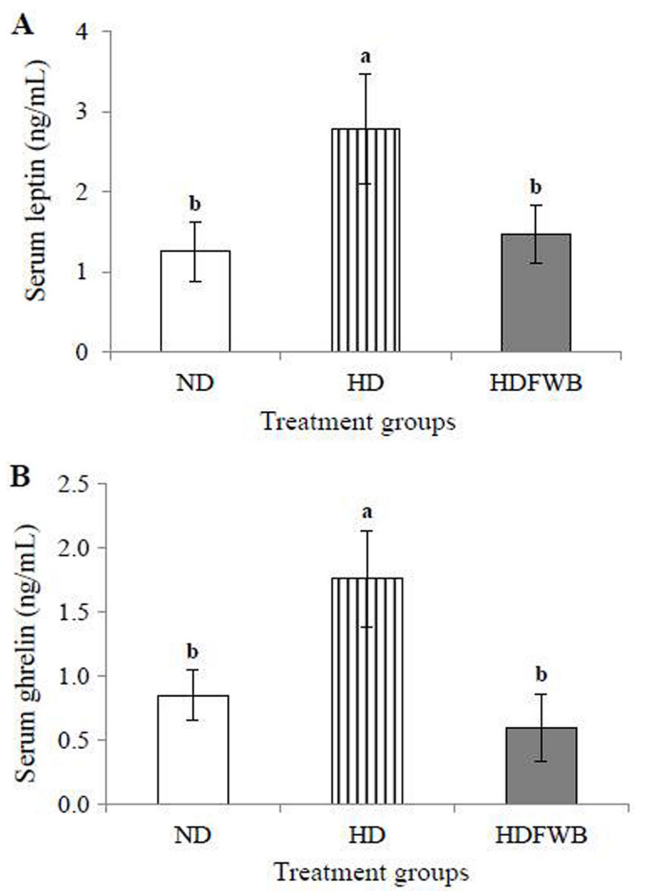

Fig. 2. Serum leptin level (A) and serum ghrelin level (B) of rats receiving normal diet (ND), high-fat diet (HD) and high-fat and fermented whey beverage diet (HDFWB). ${ }^{\mathrm{a}, \mathrm{b}}$ Means with different superscript letter among groups are significantly different at $p<0.05$ by Duncan's multiple range test. 
group compared to the ND and HDWFB groups after 4 wk of the experimental period $(p<0.05)$. There was no significant difference between the ND and HDWFB groups.

\section{Effects of the FWB on serum appetite-related hor- mones}

Fig. 2 shows the effects of FWB on the levels of appetite related hormones, leptin and ghrelin. Both leptin and ghrelin levels in the ND and HDWFB groups were not significantly different, but those in the HD group were significantly higher than those in the ND and HDWFB groups $(p<0.05)$.

\section{Discussion}

Obesity is an important topic in the world of public health and preventive medicine. It is characterized by an increase in the number and size of adipocytes at the cellular level in humans and animals (Pal et al., 2010). In the present study, the effect of FWB on obesity in male rats fed a high-fat diet was evaluated.

As in other animal studies, this study proved that a high fat diet for $4 \mathrm{wk}$ resulted in a significant increase in the rats' body weights. Daily food intake was also significantly increased in the HD group compared to the ND and HDFWB groups. This observation indicates that the increase in body weight is related to the amount of food consumption. Supplementation with FWB causes a remarkable reduction in body weight when compared to the $\mathrm{HD}$ group, showing the anti-obesity action of FWB. Shi et al. (2011) showed that a diet based on whey protein enhanced weight loss and decreased body fat content in high-fat diet fed mice compared with casein. The major whey protein fractions are $\alpha$-lactalbumin, $\beta$-lactoglobulin, and lactoferrin. $\beta$-lactoglobulin is a member of the lipocalin family, capable of trapping hydrophobic molecules, such as fatty acids and cholesterol, and consequently it may participate in reducing intestinal lipid absorption (Shi et al., 2012). It has also been recognized that microbiota and obesity or cardiovascular diseases are related. The probiotics, such as Lactobacillus and Bifidobacterium, that come from dairy products have been suggested to positively modulate gut microbiota, and consequently may help to reduce the risk of overweight or obese (MartinezGonzalez et al., 2014). Poutahidis et al., (2013) discovered, in their mouse model study, that feeding of probiotic yogurt together with general chow or with 'fast food' style chow entirely inhibited the mice's fat accumulation and body weight gain. They noted that both lactic acid bacte- ria and the resident microbiome affect the host immunity, which in turn affects obesity. Martinez-Gonzalez et al. (2014) also found that a higher consumption of yogurt was associated with a lower risk of being overweight or obese in their cohort study.

The inter-meal interval and number of meals are considered to be indicators of satiety, which indicates a prolonged fullness after meals and a reduction of motivation to reinitiate a next meal (Yu et al., 2009). The results showed that dietary supplementation with a fermented whey beverage had significant effect on the daily food intake compared to the HD and ND groups $(p<0.05)$. The decrease in the number of meals in the HDWFB group indicates that the diet reduced spontaneous meal frequency during the experiment period. Yu et al. (2009) also reported that the inter-meal interval of mice fed a whey protein diet was the longest and their number of meals was the lowest among the tested diets. These results indicate that the whey protein diet had a potent satiety effect.

Obesity is characterized not just by an increase in body weight, but also by changes in body composition, and in particular, an increase in body-fat is a key indicator of obesity (Bocarsly et al., 2010). Compared to the HD and ND group, the weights of spleen and kidney were significantly decreased in the HDFWB group. Also, there were significant decrease in the weight of liver, and the body fat pads in the abdominal and epididymal areas of the HDFWB group compared to those of the HD group. Poutahidis et al. (2013) observed that abdominal fat and subcutaneous fat accumulations were significantly reduced in mice eating purified probiotics. Martinez-Gonzalez et al. (2014) stated that the potential anti-inflammatory actions of probiotics contained in yogurt may contribute to reducing the risk of overweight/obesity, possibly as a result of their ability to reduce lipopolysaccharide production. As mentioned earlier, whey protein also contributes to the reduction of body fat accumulation.

Dyslipidemia is another important hallmark in the pathogenesis of obesity characterized by hypertriglyceridemia with decreased levels of LDL and VLDL-cholesterol (Bais et al., 2014). To investigate the effects of FWB on the improvement of lipid disorders in mice, the levels of triglycerides, total cholesterol, HDL-cholesterol, and LDL-cholesterol in serum were measured. It was observed that supplementation with FWB did significantly attenuate the serum levels of triglycerides, total cholesterol, and LDL-cholesterol. These results were in accordance with the results reported by Jacobucci et al. (2001), where the blood serum and liver cholesterol were significantly dec- 
reased in the rats on a whey protein concentrate (WPC) diet. According to Shi et al. (2012), $\beta$-lactoglobulin, one of the major whey protein fractions, is a member of the lipocalin family, capable of trapping hydrophobic molecules such as fatty acids, cholesterol, retinol, and vitamin D. Therefore, it is possible that $\beta$-lactoglobulin participates in reducing intestinal lipid absorption. Pal et al. (2010) also stated that whey protein supplementation can significantly improve metabolic risk factors associated with chronic diseases in overweight and obese individuals.

Insulin resistance is associated with a number of metabolic disorders such as obesity, hyperlipidemia, and hypertension (Bais et al., 2014). Several studies (Bais et al., 2014; Fan et al., 2014) indicated that in animal studies, high fat diets resulted in disturbance in glucose metabolism and caused glucose tolerance. Similar to their studies, the present study demonstrated a significant increase in blood glucose and serum insulin levels in the HD group, while the HDFWB group showed lowest levels (Fig. 1). These findings suggest that FWB can reduce blood glucose levels and improve insulin resistance. These results are coincident with other animal studies (Park et al., 2008; Shi et al., 2011) in which whey protein had significant effect on the decrease in blood glucose and serum insulin. Pal et al. (2010), in their clinical study, also indicated that fasting insulin levels and the homeostasis model assessment of insulin resistance scores were significantly decreased in the whey group. They explained that the improvement of insulin sensitivity in the whey protein diet group was due to the reduction in visceral fat because visceral obesity was strongly correlated with insulin resistance.

Leptin and ghrelin are two hormones that have been recognized to have a major influence on energy balance through regulation of food intake and body weight (Klok et al., 2007). Leptin, a hormone mainly produced in the adipocytes, is a mediator of long-term regulation of energy balance, suppressing food intake and thereby inducing energy expenditure and weight loss (Fradinho et al., 2014; Klok et al., 2007; Kondoh and Torii, 2008). On the other hand, ghrelin, an endogenous peptide hormone which is known as a ligand of growth hormone secretagogue receptors (GHS-Rs), is a fast-acting hormone and plays a role in meal initiation (Klok et al., 2007). It has been found that the serum leptin level is positively correlated with body fat mass (Klok et al., 2007; Kondoh and Torii, 2008). This correlation was observed in this study, as the serum leptin levels in the HDWFB group (1.46 $\pm 0.36 \mathrm{ng} \bullet$
$\mathrm{mL}^{-1}$ ) were significantly lower than those in the HD group $\left(2.79 \pm 0.69 \mathrm{ng} \cdot \mathrm{mL}^{-1}\right)$. In general, the blood level of ghrelin is increased during fasting and decreased after food intake (Klok et al., 2007: Sim et al., 2014). It has been found ghrelin to be reduced in obese humans. However, our study showed conflicting results, as the serum ghrelin levels were significantly higher in the HD group than in the other groups $(p<0.05)$ and decreased in the HDFWB group. This result agrees with those of Park et al. (2008), in which the serum ghrelin level was significantly decreased in rats fed whey protein. Therefore it refers to the ghrelin increased in obese that can be reduced by fed FWB.

\section{Conclusion}

The present study showed that FWB could suppress body weight gain, organ weight gain, and white adipose tissue formation, reduce the levels of serum lipids and appetite-related hormones, and improve insulin sensitivity in obese rats fed a high-fat diet. Both probiotics and whey protein used for the fermentation of the FWB product might contribute to the anti-obesity and lipid lowering effects.

\section{Acknowledgements}

This research was financially supported by the Ministry of Trade, Industry and Energy (MOTIE) and Korea Institute for Advancement of Technology (KIAT) through the Promoting Regional specialized Industry.

\section{Compliance with ethical guidelines}

The experimental design was approved by Experimental Animals Ethics Committee of Dankook University, Cheonan, Korea and the rats were maintained in accordance with their guidelines.

\section{References}

1. Bais, S., Singh, G. S., and Sharma, R. (2014) Antiobisity and hypolipidemic activity of Moringa oleifera leaves against high fat diet-induced obesity in rats. Adv. Biol. Article ID 162914.

2. Belobrajdic, D. P., Mclntosh, G. H., and Owens, J. A. (2004) A high-whey-protein diet reduces body weight gain and alters insulin sensitivity relative to red meat in Wistar rats. J. Nutr. 134, 1454-1458.

3. Bocarsly, M. E., Powell, E. S., Avena, N. M., and Hoebel, B. G. (2010) High-fructose corn syrup causes characteristics of 
obesity in rats: Increased body weight, body fat and triglyceride levels. Pharmacol. Biochem. Behav. 97, 101-106.

4. Cho, Y. H., Shin, I. S., Hong, S. M., and Kim, C. H. (2015) Production of functional high-protein beverage fermented with Lactic acid bacteria isolated from Korean traditional fermented food. Korean J. Food Sci. An. 35, (In press).

5. Douglas, S. M., Ortinau, L. C., Hoertel, H. A., and Leidy, H. J. (2013) Low, moderate, or high protein yogurt snacks on appetite control and subsequent eating in healthy woman. Appetite 60, 117-122.

6. Fan, S., Zhang, Y., Sun, Q., Yu, L., Li, M., Zheng, B., Wu, W., Yang, B., Li, Y., and Huang, C. (2014) Extract of okra lowers blood glucose and serum lipids in high-fat diet-induced obese C57BL/6 mice. J. Nutr. Biochem. 25, 702-709.

7. Fradinho, M. J., Correia, M. J., Gracio, V., Bliebernicht, M., Farrim, A., Mateus, L., Martin-Rosset, W., Bessa, R. J. B., and Caldeira, R. M. (2014) Effects of body condition and leptin on the reproductive performance of Lusitano mares on extensive systems. Theriogenology 81, 1214-1222.

8. Ikeda, T., Tanaka, Y., Yamamoto, K., Morii, H., Kamisako, T., and Ogawa, H. (2014) Geranium dielsianum extract powder (MISKAMISKA ${ }^{\mathrm{TM}}$ ) improves the intestinal environment through alteration of microbiota and microbial metabolites in rats. J. Funct. Foods 11, 12-19.

9. Jacobucci, H. B., Sgarbieri, V. C., Dias, N. F. G. P., Borges, P., and Tanikawa, C. (2001) Impact of different dietary protein on rat growth, blood serum lipids and protein and liver cholesterol. Nutr. Res. 21, 905-915.

10. Jakubowicz, D. and Froy, O. (2013) Biochemical and metabolic mechanisms by which dietary whey protein may combat obesity and Type 2 diabetes. J. Nutr. Biochem. 24, 1-5.

11. Jin, D., Xu, Y., Mei, X., Meng, Q., Gao, Y., Li, B., and Tu, Y. (2013) Antiobesity and lipid lowering effects of theaflavins on high-fat diet induced obese rats. J. Funct. Foods 5, 11421150.

12. Klok, M., Jakobsdottir, S., and Drent, M. L. (2007) The role of leptin and ghrelin in the regulation of food intake and body weight in humans: A review. Obes. Rev. 8, 21-34.

13. Kondoh, T. and Torii, K. (2008) MSG intake suppresses weight gain, fat deposition, and plasma leptin levels in male Sprague-Dawley rats. Physiol. Behav. 95, 135-144.

14. Lee, B. H., Lo, Y. H., and Pan, T. M. (2013) Anti-obesity activity of Lactobacillus fermented soy milk products. J. Funct. Foods 5, 905-913.

15. Martinez-Gonzalez, M. A., Sayon-Orea, C., Ruiz-Canela, M., de la Fuente, C., Gea, A., and Bes-Rastrollo, M. (2014) Yogurt consumption, weight change and risk of overweight/obesity: The SUN cohort study. Nutr. Metab. Cardiovasc. Dis. 24, 1189-1196.

16. Pal, S., Ellis, V., and Dhaliwal, S. (2010) Effects of whey protein isolate on body composition, lipids, insulin and glucose in overweight and obese individuals. Br. J. Nutr. 104, 716-723.

17. Park, J. Y., Park, M. N., Choi, Y. Y., Yun, S. S., Chun, H. N., and Lee, Y. S. (2008) Effects of whey protein hydrolysates on lipid profiles and appetite-related hormones in rats fed high fat diet. J. Korean Soc. Food Sci. Nutr. 37, 428-436.

18. Pilvi, T. K., Seppanen-Laakso, T., Simolin, H., Finckenberg, P., Huotari, A., Herzig, K. H., Korpela, R., Oresic, M., and Mervaala, E. M. (2008) Metabolomic changes in fatty liver can be modified by dietary protein and calcium during energy restriction. World J. Gastroenterol. 14, 4462-4472.

19. Poutahidis, T., Kleinewietfeld, M., Smillie, C., Levkovich, T., Perrotta, A., Bhela, S., Varian, B. J., Ibrahim, Y. M., Lakritz, J., Kearney, S. M., Chatzigiagkos, A., Hafler, D. A., Alm, E. J., and Erdman, S. E. (2013) Microbial reprogramming inhibits western diet associated obesity. PLoS One 8, e68596.

20. Rittmanic, S. (2008) U.S. whey proteins in ready-to-drink beverages. US Dairy Export. Council.

21. Sanmartin, B., Diaz, O., Rodriguez-Turienzo, L., and Cobos, A. (2013) Functional properties of caprine whey protein concentrates obtained from clarified cheese whey. Small Ruminant Res. 110, 52-56.

22. Shi, J., Ahlroos-Lehmus, A., Pilvi, T. K., Korpela, R., Tossavainen, O., and Mervaala, E. M. (2012) Metabolic effects of a novel microfiltered native whey protein in diet-induced obese mice. J. Funct. Foods 4, 440-449.

23. Shi, J., Tauriainen, E., Martonen, E., Finckenberg, P., AhlroosLehmus, A., Tuomainen, A., Pilvi, T. K., Korpela, R., and Mervaala, E. M. (2011) Whey protein isolate protects against diet-induced obesity and fatty liver formation. Int. Dairy J. 21, 513-522.

24. Siddiqui, S. M. K., Chang, E., Li, J., Burlage, C., Zou, M., Buhman, K. K., Koser, S., Donkin, S. S., and Teegarden, D. (2008) Dietary intervention with vitamin D, calcium, and whey protein reduced fat mass and increased lean mass in rats. Nutr. Res. 28, 783-790.

25. Sim, Y. B., Park, S. H., Kim, S. S., Kim, C. H., Kim, S. J., Lim, S. M., Jung, J. S., and Suh, H. W. (2014) Ghrelin administered spinally increases the blood glucose level in mice. Peptides 54, 162-165.

26. You, J. S., Lee, Y. J., Kim, K. S., Kim, S. H., and Chang, K. J. (2014) Ethanol extract of lotus (Nelumbo nucifera) root exhibits an anti-adipogenic effect in human pre-adipocytes and anti-obesity and anti-oxidant effects in rats fed a high-fat diet. Nutr. Res. 34, 258-267.

27. Yu, Y., South, T., and Huang, X. U. (2009) Inter-meal interval is increased in mice fed a high whey, as opposed to soy and gluten, protein diets. Appetite 52, 372-379.

28. Xu, S. P., Mao, X. Y., Cheng, X., and Chen, B. (2013) Ameliorating effects of casein glycomacropeptide on obesity induced by high-fat diet in male Sprague-Dawley rats. Food Chem. Toxicol. 56, 1-7. 